\title{
Promotion of self-renewal of embryonic stem cells by midkine
}

\author{
Xing $\mathrm{YAO}^{1, *}$, Zhou TAN² ${ }^{2}$ Bin GU², Rong-rong WU², Yu-kan $\mathrm{LIU}^{2}$, Li-cheng DAI ${ }^{1}$, Ming ZHANG ${ }^{2, *}$ \\ ${ }^{1}$ Huzhou Central Hospital, Huzhou 313000, China; ${ }^{2}$ College of Life Sciences, Zhejiang University, Hangzhou 310058, China
}

\begin{abstract}
Aim: To characterize the expression and function of midkine (MK) in an in vitro embryonic stem cell (ESC) culture system. Methods: To investigate the potential roles of MK, the expression of MK in ESCs was evaluated by RT-PCR and immunocytochemistry. The effects of MK on the self-renewal of ESCs were measured using alkaline phosphatase assays, immunocytochemistry, RT-PCR and colony-forming assays. The mechanism of the growth-promoting effect of MK in mESCs was assessed by cell cycle analysis and Western blot analysis.

Results: MK is expressed in mouse embryonic stem cells (mESCs), human embryonic stem cells (hESCs) and mouse embryonic fibroblasts (MEFs). MK promotes proliferation and self-renewal of mESCs both in feeder and feeder free culture systems. It also promotes self-renewal and proliferation of hESCs. Further study showed that MK promotes the growth of mESCs by inhibiting apoptosis while accelerating the progression toward the S phase, and enhances mESC self-renewal through PI3K/Akt signaling pathway. Conclusion: MK plays profound roles in ESCs. MK/PTP $\zeta$ signaling pathway is a novel pathway in the signal network maintaining pluripotency of ESCs. The results extend our knowledge on pluripotency control of ESCs and the relationship between ESCs and cancers.
\end{abstract}

Keywords: embryonic stem cells; midkine; self-renewal; mouse embryonic fibroblasts; proliferation; PI3K/Akt signaling pathway

Acta Pharmacologica Sinica (2010) 31: 629-637; doi: 10.1038/aps.2010.39

\section{Introduction}

Embryonic stem cells (ESCs) are pluripotent stem cells derived from the inner cell mass of mammalian blastocysts. They have the capacities of self-renewal and multilineage differentiation $^{[1-3]}$. Special culture conditions are required to maintain the pluripotency of ESCs. ESCs are typically maintained on a feeder layer of mitotically inactivated mouse embryonic fibroblasts (MEFs) with the addition of proper growth factors. A complicated signaling network involving Leukemia inhibitory factor (LIF), fibroblast growth factor (FGF), Activin/Nodal and Wnts serves to maintain the pluripotency of ESCs. Some of these pathways have been demonstrated to function in the self-renewal and proliferation of cancer stem cells. Therefore, it is an important task to discover and dissect new signaling pathways that maintain the pluripotency of ESCs and that delineate their relationship with cancer.

Midkine (MK) is a heparin-binding signaling molecule that regulates the proliferation and differentiation of cells through binding to its receptor, $\mathrm{PTP}^{[4]}$. MK was first isolated as a

\footnotetext{
* To whom correspondence should be addressed.

E-mail yaoy@mail.huptt.zj.cn (Xing YAO) zhangming_Is@zju.edu.cn (Ming ZHANG)

Received 2009-01-24 Accepted 2010-03-08
}

retinoic acid-responsive gene from embryonic carcinoma (EC) cells. It is highly expressed during midgestation and down-regulated at birth ${ }^{[5]}$. MK is expressed in multiple types of tumors and functions to promote their proliferation and metastasis $^{[6-11]}$. As many cancer-related molecules play significant roles in ESCs and EC cells are considered transformed ESCs, we set out to characterize the expression and function of $\mathrm{MK}$ in an in vitro ESC culture system. The hypothesis that MK-PTP $\zeta$ works by activating PI3K/AKT has been proven in several kinds of cells ${ }^{[12-14]}$. Moreover, the activation of Akt signaling has been shown to be sufficient for the pluripotency of both mouse and primate ESCs ${ }^{[15]}$. Thus, it is highly probable that MK is a critical factor for ESC self-renewal.

In our study, we demonstrate that MK promotes selfrenewal and proliferation of both mouse ESCs (mESCs) and human ESCs (hESCs). Further, we show that MK promotes the growth of mESCs by inhibiting apoptosis while accelerating progression toward the $S$ phase and enhances mESC selfrenewal through the PI3K/Akt signaling pathway.

\section{Materials and methods Reagents}

Recombinant human midkine was purchased from PeproTech (http://www.peprotech.com) and LY294002 was purchased 
from Sigma-Aldrich. MK was dissolved in distilled water to a final concentration of $0.1-1.0 \mathrm{mg} / \mathrm{mL}$, and this solution was further diluted into other aqueous buffers and stored at $4{ }^{\circ} \mathrm{C}$ for 1 week or $-20^{\circ} \mathrm{C}$ for future use.

\section{Embryonic stem cell cultures}

MEFs were prepared from $13.5 \mathrm{~d}$ post fertilization mouse embryos and cultured in Dulbecco's modified Eagle's medium (DMEM, Gibco, Grand Island, NY) supplemented with 10\% fetal bovine serum (FBS, Hyclone, Rockville, MD) and passaged every 3 days. The mESC lines D3 (ATCC, http:/ / www. atcc.org/ ) and 129J2 ${ }^{[16]}$ were cultured either feeder-free or on mitomycin-C (Sigma-Aldrich, St Louis, MO) treated MEFs in Dulbecco's modified Eagle's medium (DMEM) supplemented with 15\% FBS, $2 \mathrm{mmol} / \mathrm{L}$ L-glutamine (Gibco), $0.1 \mathrm{mmol} / \mathrm{L}$ $\beta$-mercaptoethanol (Sigma), 1\% non-essential amino acids (NEAA, Gibco), and $1000 \mathrm{U} / \mathrm{mL}$ leukemia inhibitory factor (LIF, Chemicon, Temecula, CA). MESC line D3 transfected with enhanced green fluorescence protein (EGFP) under the control of the murine Rex1 promoter (Rex1-EGFP D3) ${ }^{[17]}$ was also used for the study. Confluent cultures of mESCs were passaged with $0.25 \%$ trypsin-EDTA (Hyclone). HESC lines, HUES3 $^{[18]}$ at passage 41 and ZJUhES-1 at passage 29 , were cultured on mitomycin-C inactivated MEFs in Knockout DMEM (Gibco) supplemented with 20\% Knockout serum replacement (SR, Gibco), $2 \mathrm{mmol} / \mathrm{L}$ L-glutamine, $0.1 \mathrm{mmol} / \mathrm{L}$ $\beta$-mercaptoethanol, $1 \%$ non-essential amino acids, and 10 $\mathrm{ng} / \mathrm{mL}$ human basic fibroblast growth factor (bFGF, Invitrogen, Carlsbad, CA). For expansion, hESCs were subcultured by mechanical dissociation of colonies every 5-7 days. Tissue culture plates and dishes (Falcon, Becton-Dickinson) were coated with $0.5 \%$ gelatin (Gibco). The cells were cultured at $37^{\circ} \mathrm{C}$ and $5 \% \mathrm{CO}_{2}$ with a daily change of medium.

\section{Differentiation in vitro}

Undifferentiated mESCs were trypsinized with $0.25 \%$ trypsinEDTA, and the trypsinization was stopped by adding medium containing FBS. A previously described protocol was used to separate the mESCs from MEFs ${ }^{[19]}$. The mESCs were then collected by centrifugation and resuspended in mESC medium without LIF. For monolayer-adhesive cultures, mESCs were cultivated at very low density in plates coated with $0.5 \%$ gelatin at $37{ }^{\circ} \mathrm{C}$ and $5 \% \mathrm{CO}_{2}$. For embryoid body (EB) formation, mESCs were diluted to 300-3000 cells/mL, dropped onto the lid surface of tissue culture dishes (Falcon), and then incubated for $24-48 \mathrm{~h}$ at $37{ }^{\circ} \mathrm{C}$ with $5 \% \mathrm{CO}_{2}$. The EBs were then harvested and cultivated for another 15 days.

\section{Immunocytochemistry}

Immunocytochemical analysis was performed using a goat anti-mouse MK antibody at 1:500 dilution (Santa Cruz, Delaware Avenue, CA) and a rabbit anti-human MK monoclonal antibody at 1:50-1:500 dilution (Epitomics, California, http:/ / www.epitomics.com) to demonstrate the expression of MK in both mESCs and hESCs. A rabbit anti-Nanog antibody at 1:2000 dilution (Chemicon, Temecula, CA) was used to evaluate the expression of the ESC biomarker, Nanog. A FITC-conjugated rabbit anti-goat IgG antibody (Santa Cruz) and a goat anti-rabbit IgG antibody (Epitomics) were used as secondary antibodies, respectively. ESCs were prepared and washed once with phosphate-buffered saline (PBS). Then the cells were fixed with $4 \%$ paraformaldehyde (Sigma) for $1.5 \mathrm{~h}$ and permeabilized with 3\% Triton X-100 (Sigma) for $30 \mathrm{~min}$. Nonspecific binding was blocked with $1 \%$ bovine serum albumin (BSA, Sigma) for $30 \mathrm{~min}$. The ESCs were incubated with primary antibodies at $37^{\circ} \mathrm{C}$ for $1 \mathrm{~h}$. After being washed, secondary antibodies were added at a 1:100-1:1000 dilution and incubated at $37^{\circ} \mathrm{C}$ for another $1 \mathrm{~h}$ in the dark. Finally, cell nuclei were stained with $0.5 \mu \mathrm{g} / \mathrm{mL}$ Hoechst33258 (Sigma) for $5 \mathrm{~min}$ and examined by fluorescence microscopy (Olympus IX-70).

\section{Reverse transcription-PCR}

Total RNA was isolated from ESCs using Trizol reagent (Invitrogen). M-MLV Reverse Transcriptase (Promega) and random primers (Promega) were used for first strand cDNA synthesis according to the manufacturer's instructions. PCR was carried

Table 1. Oligonucleotide primers used in the RT-PCR.

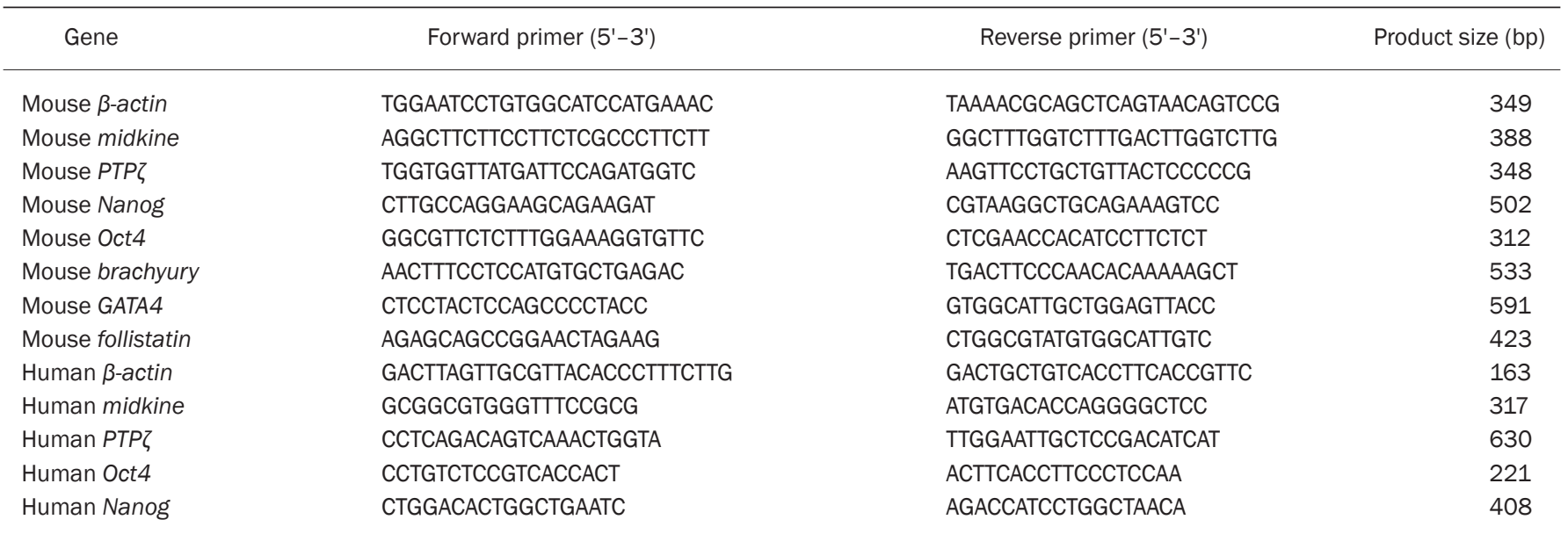


out with Taq DNA polymerase (Takara), and the target genes, primer sequences, and product sizes are listed in Table 1 . The PCR products were visualized by electrophoresis with a $1.5 \%$ agarose gel containing $0.5 \mu \mathrm{g} / \mathrm{mL}$ ethidium bromide.

\section{Alkaline phosphatase assay and colony-forming assay}

Staining for alkaline phosphatase (ALP) was achieved using a kit from Sigma-Aldrich following the instructions of the manufacturer. ALP activity was evaluated by color intensity, and pictures were taken using a microscope (Olympus BX-60). For the colony-forming assay, ESCs were diluted to 50 cells $/ \mathrm{mL}$ and $100 \mu \mathrm{L}$ was transferred to each MEF-containing well in a 96-well plate. At approximately day 6, colonies were stained for ALP. The total colonies and ALP-positive colonies were counted to calculate the colony formation rate. Three replicates of this assay were done.

\section{Western blot analysis}

Proteins were extracted by RIPA buffer $(50 \mathrm{mmol} / \mathrm{L}$ Tris$\mathrm{HCl}, \mathrm{pH} 7.4,1 \%$ Triton $\mathrm{X}-100,0.25 \%$ sodium deoxycholate, $150 \mathrm{mmol} / \mathrm{L} \mathrm{NaCl}, 1 \mathrm{mmol} / \mathrm{L}$ EGTA, 0.1\% SDS, and protease inhibitor cocktail) and separated by SDS-PAGE. The resolved proteins were transferred to PVDF membranes. Non-specific reactivity was blocked by incubating the membrane in 10 mmol/L Tris- $\mathrm{HCl}$ (pH 7.5), $150 \mathrm{mmol} / \mathrm{L} \mathrm{NaCl}$, and 2\% Tween 20 , with $4 \%$ bovine serum albumin overnight at $4{ }^{\circ} \mathrm{C}$. Diluted primary antibodies (Epitomics) were then added, followed by the addition of the secondary antibodies (Epitomics) diluted 1:5000. Detection was carried out using the ECL chemiluminescence system.

\section{Flow cytometric analysis}

Rex1-EGFP D3 cells demonstrate kinetic changes in green fluorescence during differentiation. Cells under different culture conditions were measured by flow cytometry to track EGFP expression, and from this information, a cell differentiation ratio was inferred. Approximately $5 \times 10^{6}$ cells were collected and resuspended in $500 \mu \mathrm{L}$ PBS. For all samples, $1 \times 10^{4}$ cells were analyzed on a FACSCalibur flow cytometer (BectonDickinson, Mountain View, CA), and the data were analyzed using CellQuest 3.1 software (Becton-Dickinson).

\section{Cell cycle analysis}

Cell cycle analysis was performed using propidium iodide (PI) staining for DNA quantitation ${ }^{[20]}$. Cells were harvested, washed and centrifuged at $1000 \mathrm{r} / \mathrm{min}$ for $5 \mathrm{~min}$. Subsequently, fixation was carried out with $70 \%$ ethanol at $4{ }^{\circ} \mathrm{C}$ for more than $1 \mathrm{~h}$, followed by washing with PBS. Then, the cells were resuspended in $400 \mu \mathrm{L}$ PBS with $0.05 \%$ Triton X-100, 0.1 $\mathrm{mg} / \mathrm{mL}$ DNase-free RNase A, and $25 \mu \mathrm{g} / \mathrm{mL}$ PI and incubated for $20 \mathrm{~min}$ at $37^{\circ} \mathrm{C}$ without light exposure. For all samples, $1 \times 10^{4}$ cells were analyzed using a FACSCalibur flow cytometer with CellQuest 3.1 software. The cell cycle data were processed using ModFit LT 3.2 (Verity software house).

\section{Statistical analysis}

Data were analyzed by SPSS12.0 and expressed as means \pm SD. Statistical comparisons between two groups were made using an unpaired Student $t$ test. Probability values $(P)<0.05$ and $<0.01$ were considered significant.

\section{Results}

\section{Expression of MK and PTP in an ESC culture system}

To gain insight into the function of MK in mESCs, we first examined the expression of MK in a mESC culture system. Immunofluorescent microscopy revealed the presence of the MK protein in MEFs and the D3 cell line (Figure 1A). The expression of MK in the 129J2 cell line was also detectable by immunocytochemistry (data not shown). Semi-quantitative RT-PCR was performed to assay the expression levels of MK. As shown in Figure 1B, 13.5-day embryos and primary cultures of MEFs expressed the highest levels of MK, and the expression decreased with passages. MEFs at passage 6 were used in subsequent experiments. mESCs were enriched through purification (see Materials and methods), and total RNA was isolated from these cells. RT-PCR analysis confirmed the expression of $\mathrm{MK}$ and $\mathrm{MK}$ receptor (PTP $\zeta$ ) in $\mathrm{mESC}$ lines, D3, and 129J2 (Figure 1C). A relatively high expression of MK was shown during the first 10 days of differentiation; however, the levels of MK decreased with the differentiation of mESCs during both monolayer culture (Figure 1D) and EB development (Figure 1E). The pluripotency markers, Oct4 and Nanog, were examined to evaluate the differentiation state of mESCs.

\section{MK enhances $\mathrm{mESC}$ self-renewal}

LIF and feeder cells are needed for maintaining the selfrenewal capacity of $\mathrm{mESC}^{[21]}$. To further test the effect of MK on mESC self-renewal, mESCs (D3) were cultured on MEFs in mESC medium without LIF but supplemented with increasing concentrations of MK (0-40 ng/mL) and with a daily change of the medium. The cells were passaged every 3 days. At passage 7 , the stemness of mESCs was examined by morphological characterization, ALP staining and expression of pluripotency markers such as Nanog and Oct4. As shown in Figure 2A, mESC colonies in the absence of MK or in the presence of a low concentration $(10 \mathrm{ng} / \mathrm{mL})$ of MK displayed a flattened morphology and stained weakly for ALP and Nanog, indicating spontaneous differentiation. However, mESC colonies cultured with a high concentration (20-40 ng/mL) of MK showed a typical morphology of mESC colonies, staining strongly for ALP and Nanog expression. This indicates that an elevation of MK concentration leads to an increased expression of ALP and Nanog. Therefore, MK facilitates the self-renewal of mESCs in a concentration-dependent manner. These results were further confirmed by RT-PCR examination of the expression of pluripotency markers, Oct4 and Nanog (Figure 2B). Even after being cultured in $20 \mathrm{ng} / \mathrm{mL}$ of MK for 15 passages, the mESCs sustained high levels of ALP, Nanog and Oct4 expression 

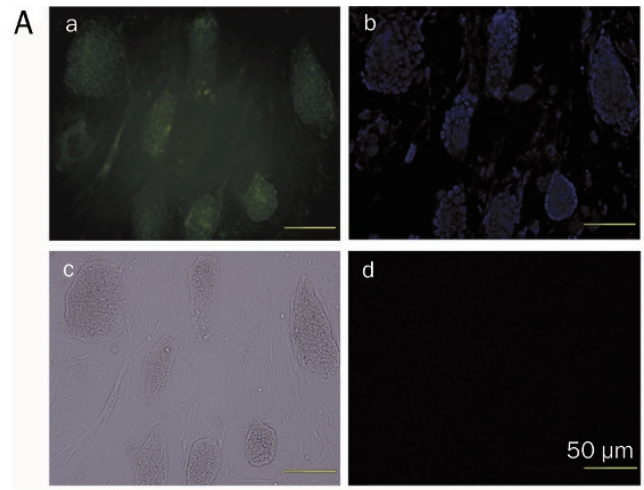

B

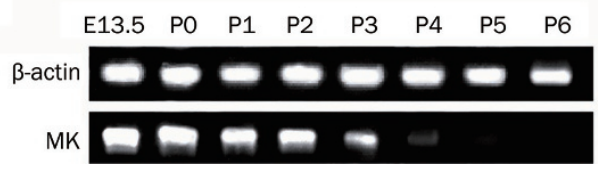

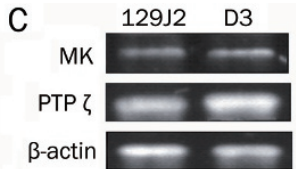
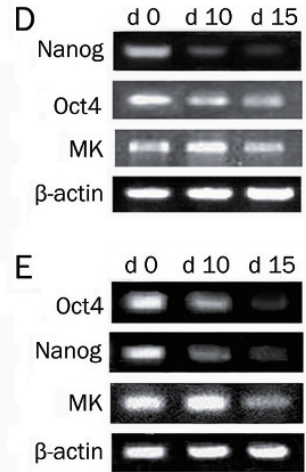

Figure 1. The presence of midkine $(M K)$ and the $M K$ receptor (PTPל) in mESCs and MEFs. (A) Immunochemical staining of the mESC line D3 and MEFs with MK antibody. (a) Immunochemical staining. (b) Cell nuclei staining with Hoechst33258. (c) Optical microscopy. (d) Isotype control, scale bars $=50 \mu \mathrm{m}$. (B) The expression levels of $M K$ in embryos of $13.5 \mathrm{~d}$ (E13.5) and MEFs at passage 0-6 (PO-P6). (C) Determination of MK and MK receptor (PTPל) expression in D3 and 129J2 cell lines by RT-PCR examination. (D) Changes of MK expression during spontaneous differentiation of monolayer cultures. (E) Changes of $\mathrm{MK}$ expression during differentiation of EB development. Oct4 and Nanog were stemness markers used to evaluate the differentiation state of mESCs. The housekeeping gene, $\beta$-actin, was used as an internal control.
(Figure 2C and Figure 2D). The same results were observed in the 129J2 cell line (data not shown).

\section{MK enhances feeder independent self-renewal of mESCs}

To further validate the effect of MK on maintaining the pluripotency of mESCs, we carried out feeder-free mESC cultures. The mESCs (D3) were cultured on dishes coated with $0.5 \%$ gelatin in different media (mESC medium without LIF, with $1000 \mathrm{U} / \mathrm{mL}$ LIF or with $1000 \mathrm{U} / \mathrm{mL}$ LIF plus $20 \mathrm{ng} / \mathrm{mL} \mathrm{MK})$. After 3 passages, mESCs grown in $1000 \mathrm{U} / \mathrm{mL}$ LIF plus 20 $\mathrm{ng} / \mathrm{mL}$ MK were still in an undifferentiated state while mESCs grown without LIF or in $1000 \mathrm{U} / \mathrm{mL}$ LIF differentiated spontaneously, as judged by morphology and the ALP assay (Figure $3 \mathrm{~A})$. The expression levels of the pluripotency markers were significantly higher in the LIF and MK group (Figure 3B). For
mESCs cultured in the feeder-free system supplemented with $1000 \mathrm{U} / \mathrm{mL}$ LIF and $20 \mathrm{ng} / \mathrm{mL}$ MK, mESCs maintained the expression of ALP and pluripotency markers after 8 passages, as shown in Figures 3C and 3D. The pluripotency of mESCs in feeder-free cultures with the addition of MK was further confirmed by EB formation (Figure 3E). As shown in Figure $3 \mathrm{~F}$, the EBs from passage $8 \mathrm{mESCs}$ in the feeder-free system expressed the molecular markers of the three germ layers, indicating the pluripotency of the cells.

\section{MK promotes growth and colony formation of mESCs}

To understand the function of MK on mESC growth and selfrenewal, growth curves and colony formation rates were examined.

After 2-day cultures, a dose-dependent increase in colony
A

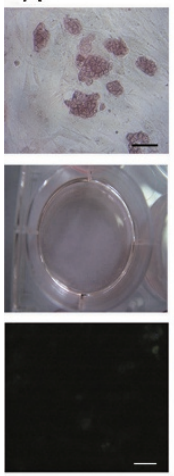

C

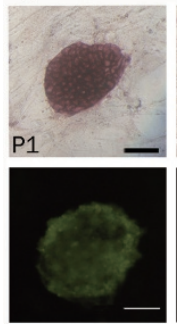

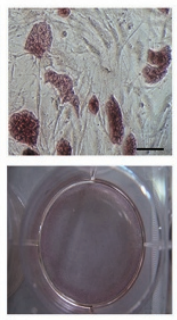
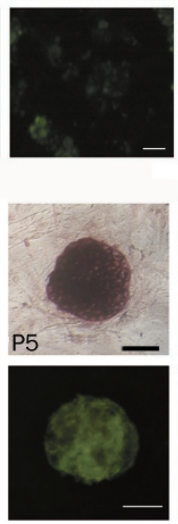
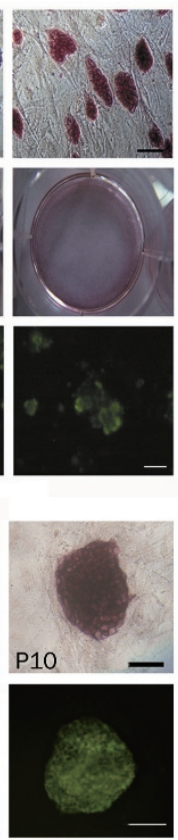
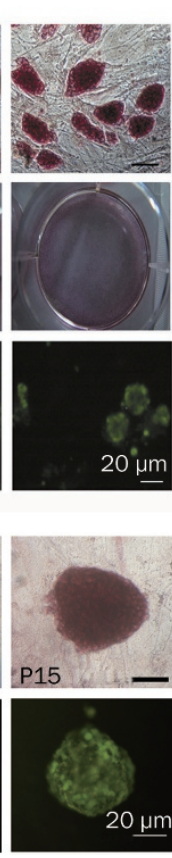

B

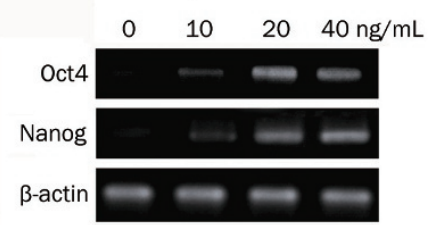

D

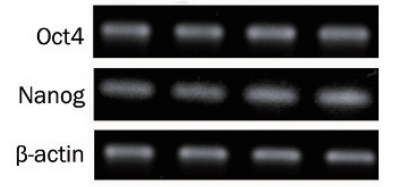

Figure 2. MK inhibits the differentiation of $m E S C s$ in long-term cultures. (A) ALP and Nanog ICC staining of $\mathrm{mESC}$ cultured with increasing concentrations of MK (from left to right: $0,10,20$, and $40 \mathrm{ng} / \mathrm{mL}$ ) at passage 7, scale bars $=20 \mu \mathrm{m}$. (B) Expression of Oct4 and Nanog in mESCs at $0-40 \mathrm{ng} / \mathrm{mL} \mathrm{MK}$ at passage 7 , with $\beta$-actin as an internal control. (C) ALP and Nanog ICC staining of mESCs with 20 $\mathrm{ng} / \mathrm{mL} \mathrm{MK}$ at passage 1-15 (from left to right: $\mathrm{P} 1$, $\mathrm{P} 5, \mathrm{P} 10$, and P15), scale bars $=20 \mu \mathrm{m}$, and (D) the expression of pluripotency markers Oct4 and Nanog. 
A

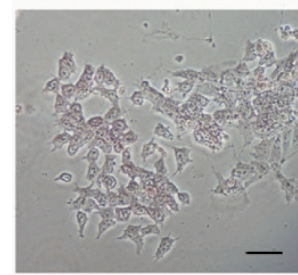

NA

C
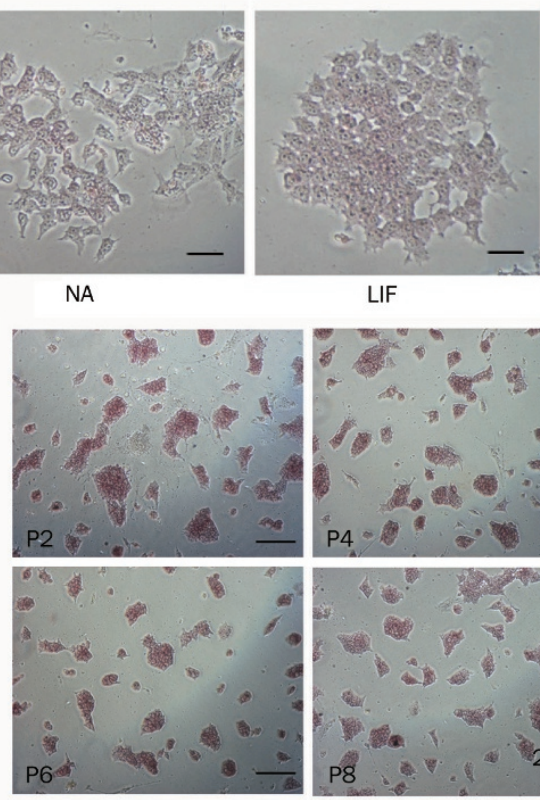

LIF

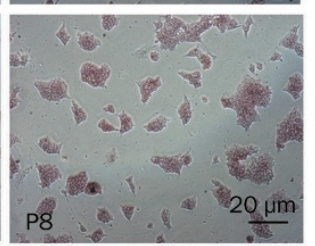

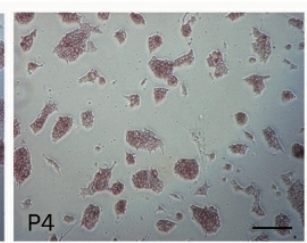

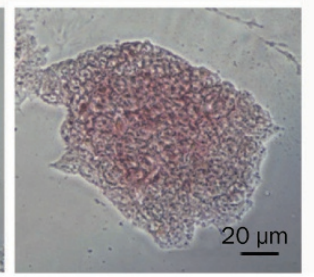

LIF+MK
B

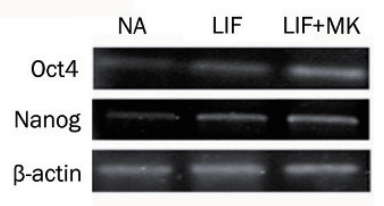

D

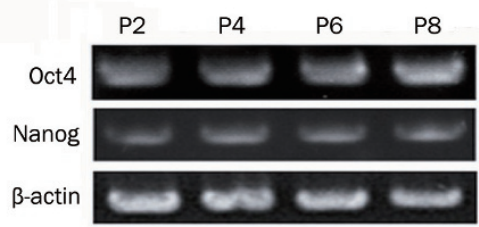

$\mathrm{F}$

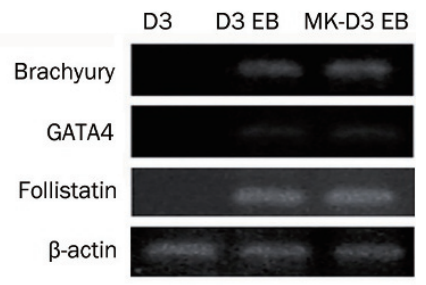

Figure 3. MK induces feeder independent self-renewal of mESCs. (A) The ALP staining of mESCs cultured in mESC medium with different combination of cell factors (NA: no factors, LIF: $1000 \mathrm{U} / \mathrm{mL}$ LIF, LIF+MK: $1000 \mathrm{U} / \mathrm{mL}$ LIF plus $20 \mathrm{ng} / \mathrm{mL} \mathrm{MK}$ ), scale bars=20 $\mu \mathrm{m}$, and (B) the expression levels of Oct4 and Nanog ( $\beta$-actin as an internal standard). (C) ALP staining of mESCs cultured in mESC medium with $1000 \mathrm{U} / \mathrm{mL} \mathrm{LIF} \mathrm{plus} 20 \mathrm{ng} / \mathrm{mL} \mathrm{MK}$ at passage 2-8 (P2-P8), scale bars $=20 \mu \mathrm{m}$, and (D) the expression of stemness markers ( $\beta$-actin as an internal standard). (E) The EB formation of mESCs (D3), scale bars $=200 \mu \mathrm{m}$, cultured long-term in feeder-free $\mathrm{mESC}$ medium with $1000 \mathrm{U} / \mathrm{mL} \mathrm{LIF} \mathrm{plus} 20 \mathrm{ng} / \mathrm{mL}$ MK and (F) the expression of three germ layer markers in these EBs.

diameter was observed in the presence of MK (Figure 4A). The growth-enhancing effect of MK was further confirmed by the growth curves under different concentrations of MK in the absence of LIF (Figure 4B). A colony formation assay is a basic assay to test the self-renewal capability of stem cells. As shown in Figure 4C and 4D, MK established both the general colony formation rate and the formation rate of ALP positive colonies. These results indicate that MK can promote both the proliferation and the self-renewal of mESCs.

\section{MK promotes growth by preventing apoptosis and regulating} progression to the $\mathrm{S}$ phase

MK may promote the proliferation of mESCs by inhibiting apoptosis. To further understand the mechanism of the growth-promoting effect of MK in mESCs, cell cycle analysis was performed using flow cytometry. As shown in Figure $5 \mathrm{~B}$, after 3 days, mESCs cultured in MK-containing medium showed significantly low levels of apoptosis compared with the controls. The number of $S$ phase cells was about twice as high in MK-containing medium as in the controls. Therefore, it appears that MK promotes the growth of mESCs mainly by inhibiting apoptosis and inducing the $\mathrm{G}_{1}-\mathrm{S}$ phase transition.

\section{MK-PTPろ pathway}

Previous studies revealed that MK binds to protein-tyrosine

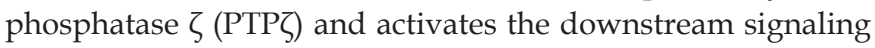
system through the Src family kinases, PI3K and MAPK ${ }^{[22]}$. To evaluate the possibility that MK enhances mESC self-renewal via the PI3K/AKT pathway, we first tested the levels of phosphorylated AKT by Western blotting. A stronger p-AKT band was observed in the presence of MK compared with the controls (Figure 5E). We then treated Rex1-EGFP D3 cells with a specific inhibitor of PI3K (LY294002) in the presence of MK. There was a significant inhibition of self-renewal after 2 days, as judged by fluorescence (Figure 5C). The results were further confirmed by flow cytometric analysis of GFP positive cells after 3 days of culture (Figure 5D). Cytotoxic effects of the inhibitor were not observed. These results indicate the involvement of the PI3K/AKT pathway in MK-stimulated self-renewal of mESCs. 
A

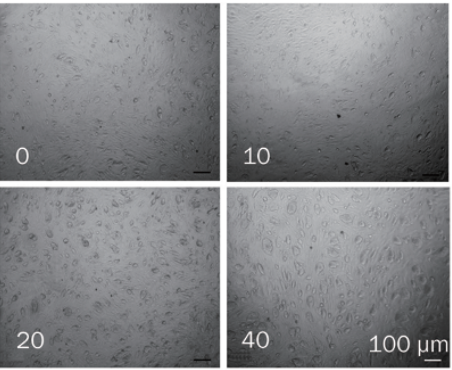

C

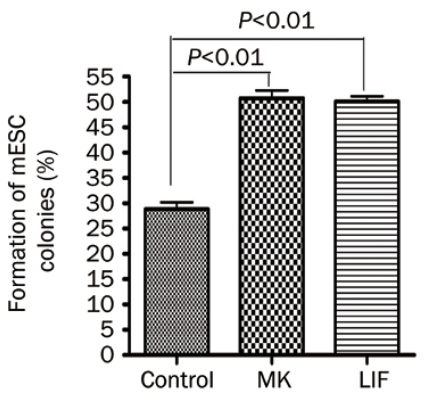

B
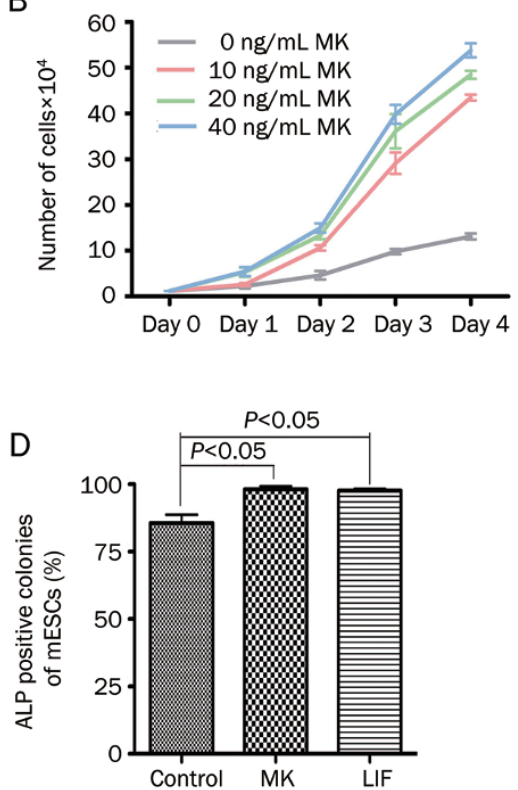

Figure 4. Promotion of $m E S C$ growth by MK. (A) The mESCs (D3) cultured on MEFs for $2 \mathrm{~d}$ in mESC medium supplemented with MK at different concentrations (0: $0 \mathrm{ng} / \mathrm{mL} \mathrm{MK,} \mathrm{10:} 10 \mathrm{ng} / \mathrm{mL}, 20: 20$ $\mathrm{ng} / \mathrm{mL}, 40: 40 \mathrm{ng} / \mathrm{mL}$ ), scale bars $=100 \mu \mathrm{m}$. (B) Cell growth curves of mESCs under different culture conditions. (C) Colony forming rate of mESCs (Control: no MK and no LIF, MK: 20 ng/mL MK, LIF: $1000 \mathrm{U} / \mathrm{mL}$ LIF). (D) The rate of ALP positive colonies among colonies of mESCs (Control: no MK and no LIF, MK: $20 \mathrm{ng} / \mathrm{mL}$ MK, LIF: $1000 \mathrm{U} / \mathrm{mL}$ LIF). Error bar=SD of triplicate experiments.
A

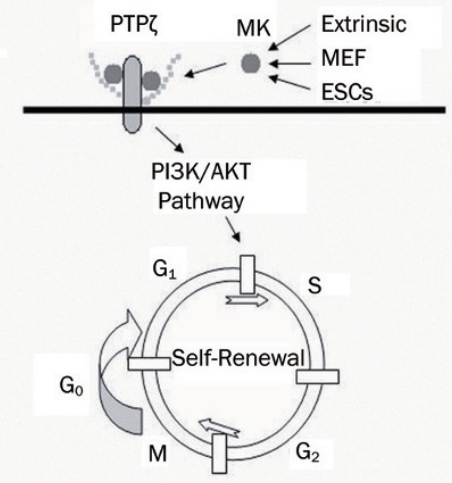

C
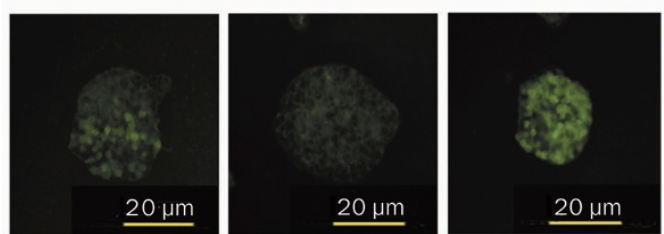

\section{$\mathrm{MK}$}
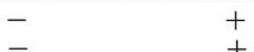

+
+

$+$
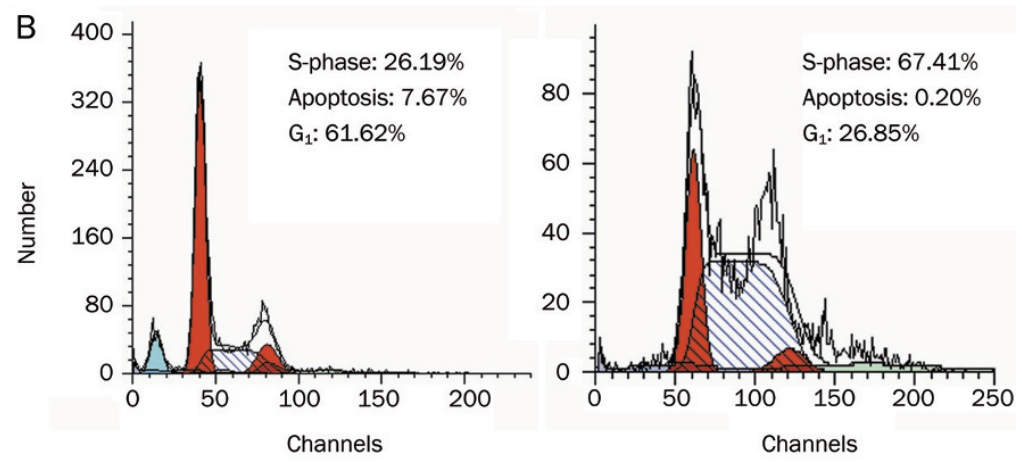

D
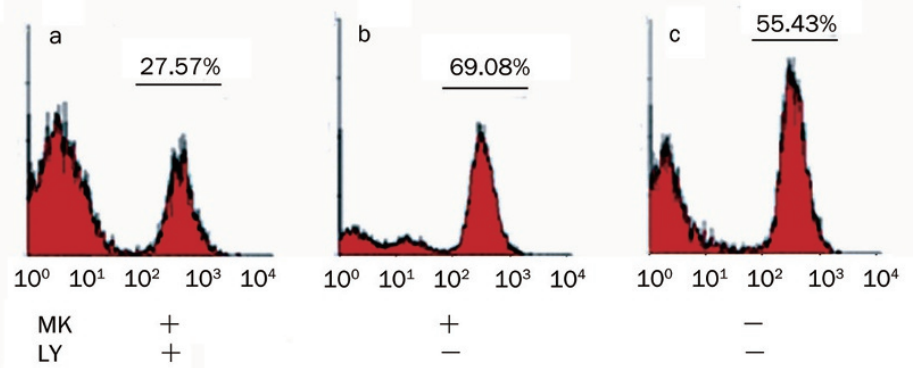

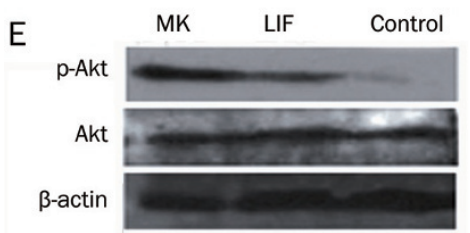

Figure 5. The possible mechanisms by which MK functions in mESCs. (A) The possible mechanism of action of MK via the PI3K/AKT pathway, with PTP as the MK receptor. (B) Cell cycle analysis of mESCs cultured in mESC medium without LIF and with $20 \mathrm{ng} / \mathrm{mL}$ MK. (C) Inhibition of MK-induced self-renewal of mESCs by a specific PI3K inhibitor (MK: $20 \mathrm{ng} / \mathrm{mL}$ MK, LY: $2 \mu \mathrm{g} / \mathrm{mL}$ LY294002), scale bars=20 $\mu \mathrm{m}$. (D) The percentage of GFP positive cells in mESCs with different treatments. (E) Western blot showing the addition of MK, resulting in increased phosphorylation of AKT. 
A
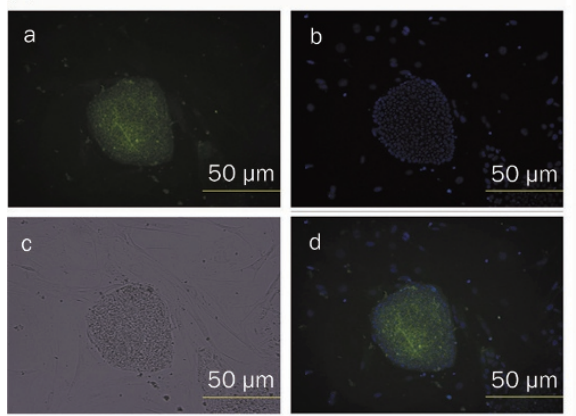

C
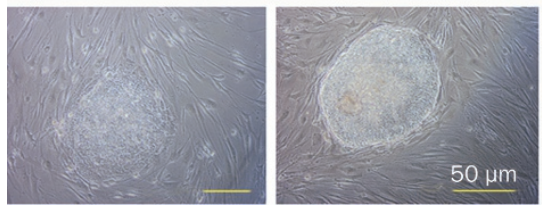

B

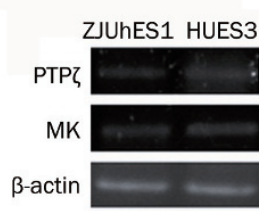

D

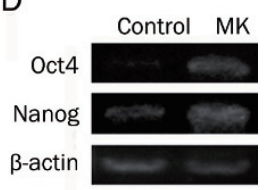

Figure 6. MK enhances self-renewal of hESCs. (A) The presence of MK protein in hESCs (HUES3): (a) Immunochemical staining. (b) Cell nuclei staining with Hoechst33258. (c) Optical microscopy. (d) Overlap of (1) and (2). (B) The expression of MK and MK receptor PTP $\zeta$ in hESCs ( $\beta$-actin as an internal control). (C) Without additional bFGF in hESC medium, $40 \mathrm{ng} / \mathrm{mL}$ MK promoted self-renewal of hESCs on feeders (right), control without MK (left). (D) the expression of pluripotency markers Oct4 and Nanog ( $\beta$-actin as an internal control). Scale bars $=50 \mu \mathrm{m}$.

\section{MK enhances self-renewal of hESCs}

MK is a member of the pleiotrophin (PTN)/MK family. It is $50 \%$ homologous to PTN at the amino acid level and shares the genomic organization and protein structure of PTN. PTN has been shown to be expressed in hESCs and to use PTP $\zeta$ to activate PI3K/AKT to enhance the long-term expansion of hESCs $^{[23]}$. To examine the effects of MK signaling on hESCs, the expression of MK on hESCs, HUES3 and ZJUhES-1, was tested. The presence of MK protein in hESCs (HUES3), as shown in Figures 6A and 6B, reveals the expression of MK and MK receptor PTP $\zeta$ in hESCs. We further demonstrated that without additional bFGF, $40 \mathrm{ng} / \mathrm{mL}$ MK promotes selfrenewal of hESCs through 3 passages, as judged by morphology and pluripotency marker expression (Figures 6C and 6D).

\section{Discussion}

Multiple signaling pathways are involved in the self-renewal of ESCs, but the exact roles of various proteins are still poorly understood. Leukemia inhibitory factor (LIF), an interleukin 6 class cytokine, sustains the self-renewal of mESCs through activation of the Stat3 pathway ${ }^{[21,24-26]}$ by binding to a specific LIF receptor (LIFR), which forms a heterodimer with GP130 ${ }^{[27-28]}$. However, LIF is not sufficient to maintain the pluripotency of hESCs ${ }^{[29-30]}$. Previous research suggests that fibroblast growth factor (FGF) signaling plays a role in supporting the self-renewal of hESCs, but the mechanisms are not clearly defined ${ }^{[31-32]}$. The $\mathrm{Wnt} / \beta$-catenin pathway is also involved in the short-term maintenance of the undifferentiated

status of both mouse and human ESCs ${ }^{[33]}$. Furthermore, bone morphogenetic protein (BMP) has been reported to induce Id proteins to maintain self-renewal of $\mathrm{mESCs}^{[34]}$. The BMP pathway has been proven to promote differentiation into trophoblasts in hESCs ${ }^{[35]}$. Oct3/4 (a member of POU family) and the homeo-box genes nanog and sox2 (also known as SRY-box 2) are critical for the maintenance of pluripotency of ESCs ${ }^{[36-40]}$. Nanog overexpression is sufficient for the self-renewal of mESCs in the absence of $\operatorname{LIF}^{[40]}$. Sox2 synergizes with Oct3/4 to activate transcription of target genes such as Fgf4 and $\operatorname{Rex} 1^{[36,41]}$. Extrinsic and intrinsic factors co-operate to form a complex network that regulates the pluripotency of ESCs.

MK, a heparin-binding developmentally regulated growth factor, has been reported to promote the survival, growth and migration of many cell types, including neuronal cells, endothelial cells and leukocytes ${ }^{[22,42]}$. Some studies show that MK functions by promoting S-phase progression and inhibiting apoptosis ${ }^{[43]}$. We demonstrate that MK promotes the growth of ESCs by preventing apoptosis and inducing the $\mathrm{G}_{1}-\mathrm{S}$ phase transition. Additionally, $\mathrm{MK}$ has been shown

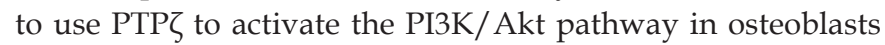
and neurons ${ }^{[12-14]}$. Our study demonstrates that MK enhances the self-renewal of mESCs primarily through the PI3K/Akt pathway. In a recent study, the activation of the PI3K/Akt pathway has been shown to be sufficient for sustaining the self-renewal of murine and primate ESCs ${ }^{[15]}$. PTN and MK are 50 percent homologous in amino acid sequence and share the same receptors. In a recent study, PTN has been reported to work as a self-renewal enhancer in hESCs ${ }^{[23]}$. In our study, we found that MK has similar effects as PTN in the hESC culture system. However, further research is needed to assess the function and mechanism of midkine in the embryonic stem cell culture system.

MK expression is up-regulated in the majority of human tumors, including neuroblastomas ${ }^{[44]}$, head and neck cancer, esophageal cancer, lung cancer ${ }^{[9]}$, breast cancer ${ }^{[45]}$, bladder can$\operatorname{cer}^{[46]}$, Wilms' tumor, gastrointestinal cancers ${ }^{[10-11]}$ and a variety of tumor-derived cell lines ${ }^{[9-10,45,47,48]}$. However, the expression of MK is highly restricted in normal adult tissues, making it a potential marker for cancers. Our finding that MK is expressed and functional in mouse and human ESCs indicates a new molecular link between stem cells and cancer. It will be an important task to characterize the expression and function of midkine in cancer stem cells.

In conclusion, MK plays a significant role in ESCs. Our finding that MK is a proliferative agent for ESCs in vitro sheds insight into the mechanisms by which ESCs maintain their growth in vitro. In addition, this study demonstrates that the $\mathrm{MK} / \mathrm{PTP} \zeta$ signaling pathway is a previously unknown pathway in the signaling network that maintains the pluripotency of ESCs. This finding extends our knowledge of pluripotency control in ESCs and of the relationship between ESCs and cancers.

\section{Acknowledgements}

We thank Drs Xiao HUANG, Chen LUO, and Wan-xi YANG 
for help reviewing the manuscript. We greatly appreciate the gift of the hESC line (HUES3) from Dr Douglas MELTON (Department of Molecular and Cellular Biology, Harvard University). This work was supported by the Key Science and Technology Foundation of Zhejiang Province (№ J 2002057930116).

\section{Author contribution}

Xing YAO, Ming ZHANG, and Zhou TAN designed and performed the research. Bin GU, Rong-rong WU, and Yu-kan LIU contributed new analytic tools. Xing YAO, Li-cheng DAI, and Zhou TAN analyzed the data and wrote the paper.

\section{References}

1 Martin GR. Isolation of a pluripotent cell line from early mouse embryos cultured in medium conditioned by teratocarcinoma stem cells. Proc Natl Acad Sci USA 1981; 78: 7634-8.

2 Evans MJ, Kaufman MH. Establishment in culture of pluripotential cells from mouse embryos. Nature 1981; 292: 154-6.

3 Thomson JA, Itskovitz-Eldor J, Shapiro SS, Waknitz MA, Swiergiel JJ, Marshall VS, et al. Embryonic stem cell lines derived from human blastocysts. Science 1998; 282: 1145-7.

4 Maeda N, Ichihara-Tanaka K, Kimura T, Kadomatsu K, Muramatsu T, Noda M. A receptor-like protein-tyrosine phosphatase PTPzeta/ RPTPbeta binds a heparin-binding growth factor midkine. Involvement of arginine 78 of midkine in the high affinity binding to PTPzeta. J Biol Chem 1999; 274: 12474-9.

5 Kadomatsu K, Tomomura M, Muramatsu T. cDNA cloning and sequencing of a new gene intensely expressed in early differentiation stages of embryonal carcinoma cells and in mid-gestation period of mouse embryogenesis. Biochem Biophys Res Commun 1988; 151 : 1312-8.

6 Kadomatsu K, Muramatsu T. Midkine and pleiotrophin in neural development and cancer. Cancer Lett 2004; 204: 127-43.

7 Kurtz A, Schulte AM, Wellstein A. Pleiotrophin and midkine in normal development and tumor biology. Crit Rev Oncog 1995; 6: 151-77.

8 Miyashiro I, Kaname T, Shin E, Wakasugi E, Monden T, Takatsuka Y, et al. Midkine expression in human breast cancers: expression of truncated form. Breast Cancer Res Treat 1997; 43: 1-6.

9 Garver RI Jr, Chan CS, Milner PG. Reciprocal expression of pleiotrophin and midkine in normal versus malignant lung tissues. Am J Respir Cell Mol Biol 1993; 9: 463-6.

10 Tsutsui J, Kadomatsu K, Matsubara S, Nakagawara A, Hamanoue M, Takao S, et al. A new family of heparin-binding growth/differentiation factors: increased midkine expression in Wilms' tumor and other human carcinomas. Cancer Res 1993; 53: 1281-5.

11 Aridome K, Tsutsui J, Takao S, Kadomatsu K, Ozawa M, Aikou T, et al. Increased midkine gene expression in human gastrointestinal cancers. Jpn J Cancer Res 1995; 86: 655-61.

12 Owada K, Sanjo N, Kobayashi T, Mizusawa H, Muramatsu H, Muramatsu $\mathrm{T}$, et al. Midkine inhibits caspase-dependent apoptosis via the activation of mitogen-activated protein kinase and phosphatidylinositol 3-kinase in cultured neurons. J Neurochem 1999; 73: 2084-92.

13 Qi M, Ikematsu S, Maeda N, Ichihara-Tanaka K, Sakuma S, Noda M, et al. Haptotactic migration induced by midkine. Involvement of proteintyrosine phosphatase zeta. Mitogen-activated protein kinase, and phosphatidylinositol 3-kinase. J Biol Chem 2001; 276: 15868-75.

14 Stoica GE, Kuo A, Powers C, Bowden ET, Sale EB, Riegel AT, et al. Midkine binds to anaplastic lymphoma kinase (ALK) and acts as a growth factor for different cell types. J Biol Chem 2002; 277 : 35990-8.

15 Watanabe S, Umehara H, Murayama K, Okabe M, Kimura T, Nakano T. Activation of Akt signaling is sufficient to maintain pluripotency in mouse and primate embryonic stem cells. Oncogene 2006; 25: 2697-707.

16 Jiang Z, Wu R, Yuan Y, Chen L, Zhang M. Research on the high efficient methodology of Establishment of 129S1/SvImJ murine embryonic stem cells. J Zhejiang Univ (Science Edition) 2005; 32: 574-78.

17 Chen X, Wu R, Feng S, Gu B, Dai L, Zhang M, et al. Single cell derived murine embryonic stem cell clones stably express Rex1-specific green fluorescent protein and their differentiation study. Biochem Biophys Res Commun 2007; 362: 467-73.

18 Cowan CA, Klimanskaya I, McMahon J, Atienza J, Witmyer J, Zucker JP, et al. Derivation of embryonic stem-cell lines from human blastocysts. N Engl J Med 2004; 350: 1353-6.

$19 \mathrm{Xu} \mathrm{C}$, Huang $\mathrm{H}, \mathrm{Yu} \mathrm{H}$, Zhao X. The study of separating murine embryonic fibroblast from embryonic stem cells by the differential adhesion method. Fen Zi Xi Bao Sheng Wu Xue Bao 2006; 39: 477 81.

20 Nicoletti I, Migliorati G, Pagliacci MC, Grignani F, Riccardi C. A rapid and simple method for measuring thymocyte apoptosis by propidium iodide staining and flow cytometry. J Immunol Methods 1991; 139: 271-9.

21 Stewart CL, Kaspar P, Brunet LJ, Bhatt H, Gadi I, Kontgen F, et al. Blastocyst implantation depends on maternal expression of leukaemia inhibitory factor. Nature 1992; 359: 76-9.

22 Muramatsu T. Midkine and pleiotrophin: two related proteins involved in development, survival, inflammation and tumorigenesis. J Biochem 2002; 132: 359-71.

23 Soh BS, Song CM, Vallier L, Li P, Choong C, Yeo BH, et al. Pleiotrophin enhances clonal growth and long-term expansion of human embryonic stem cells. Stem Cells 2007; 25: 3029-37.

24 Smith AG, Heath JK, Donaldson DD, Wong GG, Moreau J, Stahl M, et al. Inhibition of pluripotential embryonic stem cell differentiation by purified polypeptides. Nature 1988; 336: 688-90.

25 Williams RL, Hilton DJ, Pease S, Willson TA, Stewart CL, Gearing DP, et al. Myeloid leukaemia inhibitory factor maintains the developmental potential of embryonic stem cells. Nature 1988; 336: 684-7.

26 Smith PD, Crompton MR. Expression of v-src in mammary epithelial cells induces transcription via STAT3. Biochem J 1998; 331: 381-5.

27 Ernst M, Oates A, Dunn AR. Gp130-mediated signal transduction in embryonic stem cells involves activation of Jak and Ras/mitogenactivated protein kinase pathways. J Biol Chem 1996; 271: 3013643.

28 Inle JN. Janus kinases in cytokine signalling. Philos Trans R Soc Lond B Biol Sci 1996; 351: 159-66.

29 Daheron L, Opitz SL, Zaehres H, Lensch MW, Andrews PW, ItskovitzEldor J, et al. LIF/STAT3 signaling fails to maintain self-renewal of human embryonic stem cells. Stem Cells 2004; 22: 770-8.

30 Humphrey RK, Beattie GM, Lopez AD, Bucay N, King CC, Firpo MT, et al. Maintenance of pluripotency in human embryonic stem cells is STAT3 independent. Stem Cells 2004; 22: 522-30.

31 Amit M, Carpenter MK, Inokuma MS, Chiu CP, Harris CP, Waknitz MA, et al. Clonally derived human embryonic stem cell lines maintain pluripotency and proliferative potential for prolonged periods of culture. Dev Biol 2000; 227: 271-8.

32 Xu C, Inokuma MS, Denham J, Golds K, Kundu P, Gold JD, et al. Feeder-free growth of undifferentiated human embryonic stem cells. Nat Biotechnol 2001; 19: 971-4. 
33 Sato N, Meijer L, Skaltsounis L, Greengard P, Brivanlou AH. Maintenance of pluripotency in human and mouse embryonic stem cells through activation of Wnt signaling by a pharmacological GSK-3specific inhibitor. Nat Med 2004; 10: 55-63.

34 Ying QL, Nichols J, Chambers I, Smith A. BMP induction of Id proteins suppresses differentiation and sustains embryonic stem cell selfrenewal in collaboration with STAT3. Cell 2003; 115: 281-92.

35 Xu RH, Chen X, Li DS, Li R, Addicks GC, Glennon C, et al. BMP4 initiates human embryonic stem cell differentiation to trophoblast. Nat Biotechnol 2002; 20: 1261-4.

36 Yuan H, Corbi N, Basilico C, Dailey L. Developmental-specific activity of the FGF-4 enhancer requires the synergistic action of Sox2 and Oct-3. Genes Dev 1995; 9: 2635-45.

37 Nichols J, Zevnik B, Anastassiadis K, Niwa H, Klewe-Nebenius $D$, Chambers I, et al. Formation of pluripotent stem cells in the mammalian embryo depends on the POU transcription factor Oct4. Cell 1998; 95: 379-91.

38 Avilion AA, Nicolis SK, Pevny LH, Perez L, Vivian N, Lovell-Badge R. Multipotent cell lineages in early mouse development depend on SOX2 function. Genes Dev 2003; 17: 126-40.

39 Chambers I, Colby D, Robertson M, Nichols J, Lee S, Tweedie S, et al. Functional expression cloning of Nanog, a pluripotency sustaining factor in embryonic stem cells. Cell 2003; 113: 643-55.

40 Mitsui K, Tokuzawa Y, Itoh H, Segawa K, Murakami M, Takahashi $\mathrm{K}$, et al. The homeoprotein Nanog is required for maintenance of pluripotency in mouse epiblast and ES cells. Cell 2003; 113: 63142.

41 Ben-Shushan E, Thompson JR, Gudas L, Bergman Y. Rex-1, a gene encoding a transcription factor expressed in the early embryo, is regulated via Oct-3/4 and Oct- 6 binding to an octamer site and a novel protein, Rox-1, binding to an adjacent site. Mol Cell Biol 1998; 18: $1866-78$.

42 Dai LC, Wang X, Yao X, Lu YL, Ping JL, He JF. Antisense oligonucleotides targeting midkine induced apoptosis and increased chemosensitivity in hepatocellular carcinoma cells. Acta Pharmacol Sin 2006; 27: 1630-6.

43 Mirkin BL, Clark S, Zheng X, Chu F, White BD, Greene M, et al. Identification of midkine as a mediator for intercellular transfer of drug resistance. Oncogene 2005; 24: 4965-74.

44 Nakagawara A, Milbrandt J, Muramatsu T, Deuel TF, Zhao H, Cnaan A, et al. Differential expression of pleiotrophin and midkine in advanced neuroblastomas. Cancer Res 1995; 55: 1792-7.

45 Garver RI Jr, Radford DM, Donis-Keller H, Wick MR, Milner PG. Midkine and pleiotrophin expression in normal and malignant breast tissue. Cancer 1994; 74: 1584-90.

46 O'Brien T, Cranston D, Fuggle S, Bicknell R, Harris AL. The angiogenic factor midkine is expressed in bladder cancer, and overexpression correlates with a poor outcome in patients with invasive cancers. Cancer Res 1996; 56: 2515-8.

47 Kitamura M, Shirasawa T, Mitarai T, Muramatsu T, Maruyama N. A retinoid responsive cytokine gene, $\mathrm{MK}$, is preferentially expressed in the proximal tubules of the kidney and human tumor cell lines. Am J Pathol 1993; 142: 425-31.

48 Dai LC, Wang X, Yao X, Min LS, Ping JL, He JF. Antisense oligonucleotides targeting midkine inhibit tumor growth in an in situ human hepatocellular carcinoma model. Acta Pharmacol Sin 2007; 28: 453-8. 